\title{
Evaluation of the Algorithm for Forest Logging Detection based on Earth Observation Data
}

\author{
Tatiana S. Khovratovich, Anna A. Ivanova, Sergey A. Bartalev \\ Space Research Institute, Russian Academy of Sciences, Moscow, Russia \\ kurat@smis.iki.rssi.ru
}

\begin{abstract}
The paper is devoted to application the method of change detection in forest using Earth observation data for detecting clear-cutting and selective logging. The investigated method of detecting changes was tested on test sites in Primorsky Krai and the Republic of Udmurtia. Using the Landsat 8 and Sentinel-2 satellite data processed and, forest change maps related to logging in year 2016 were developed over the test areas. The paper compares the obtained change areas with official logging statistics and Global Forest Change project data. The difference of detected forest changes in two test sites are analyzed. Special attention is paid to assessing the impact of the terrain on the accuracy and completeness of forest change detection.
\end{abstract}

Keywords: change detection, logging, forest cover, remote sensing, topographic correction, satellite data processing 


\title{
АНАЛИЗ РЕЗУЛЬТАТОВ ПРИМЕНЕНИЯ АЛГОРИТМА ДЕТЕКТИРОВАНИЯ РУБОК ЛЕСА ПО СПУТНИКОВЫМ ДАННЫМ ДИСТАНЦИОННОГО ЗОНДИРОВАНИЯ
}

\author{
Т.С. Ховратович, А.А. Иванова, С.А. Барталев \\ Институт космических исследований РАН, Москва, Россия \\ kurat@smis.iki.rssi.ru
}

\begin{abstract}
Статья посвящена оценке возможности применения метода выявления изменений лесов по данным дистанционного зондирования из космоса для детектирования сплошных и выборочных рубок леса. Исследуемый метод выявления изменений был протестирован на тестовых участках в Приморском крае и Республике Удмуртия. По результатам интерактивной обработки спутниковых данных Landsat 8 и Sentinel-2 построены карты изменений лесов тестовых участков, вызванных их рубкой в 2016 году. В статье проведено сравнение полученных данных с данными официальной статистики по площадям рубок и картами, полученными в рамках проекта Global Forest Change. Анализируются основные причины различия точности детектирования изменений на двух тестовых участках: доминирующий способ рубки, пространственное разрешение спутниковых данных, выбор даты съемки и другие. В статье уделяется внимание вопросам оценки влияния рельефа местности на точность и полноту детектирования изменений в лесах и методам радиометрической коррекции топографических искажений спутниковых изображений.
\end{abstract}

Ключевые слова: выявление изменений, рубка леса, лесной покров, дистанционное зондирование, топографическая коррекция, обработка спутниковых данных

\section{Введение}

Данные дистанционного зондирования Земли (ДЗ3) являются одним из основных источников регулярно обновляемой информации об изменениях лесного покрова. Разработанный метод детектирования рубок леса по данным ДЗЗ основан на подпиксельной оценке проективного покрытия древесного полога леса с использованием пар разновременных спутниковых изображений. С помощью заданных значений коэффициентов спектральной яркости покрытых лесом и безлесных участков для каждого из изображений, а также линейной модели спектральных смесей для каждого пикселя входного изображения оценивается доля площади пикселя, занимаемая древесным пологом леса. Выявление изменений основано на анализе гистограммы разности разновременных оценок проективного покрытия леса. Результаты, получаемые данным методом, характеризуют долю вырубленного леса на соответствующей пикселу территории.

В среде информационной системы «Вега-Приморье», созданной для мониторинга лесов Приморского края [1], реализован инструмент детектирования изменений в лесу, в основе 
которого лежит представленный выше метод. Инструмент позволяет использовать спутниковые данные, предоставляемые Центром коллективного пользования (ЦКП) «ИКИ-Мониторинг» [2] и строить на их основе каты изменений лесного покрова. Пользователь выбирает спутниковые данные для обработки, задает эталонные участки для двух классов «лес» и «подстилающая поверхность» или выбирает обработку без задания эталонов, и запускает автоматическую процедуру детектирования изменений. Даты выбранных спутниковых данных задают временной интервал, в котором ищутся изменения. В результате работы процедуры строится попиксельная маска изменений для обрабатываемого участка, произошедших в заданном временном интервале, которая затем векторизуется и вносится в базу данных информационной системы.

Согласно лесоводческой классификации по способу рубки все вырубки леса делятся на сплошные и выборочные. При сплошной рубке древостой на лесосеке вырубается в один приём с сохранением для воспроизводства лесов отдельных деревьев и кустарников. Данный вид рубки приводит к смене типа покрова, а следовательно значительным изменениям спектральноотражательных характеристик поверхности. Часто рубки имеют характерную прямоугольную форму и достаточно существенные размеры (10-50 га), поэтому легко визуально интерпретируются по спутниковым данным Landsat-OLI или Sentinel-2 [3]. Некоторые сплошные рубки связаны с прокладкой дорог, трубопроводных трасс, линий электропередач, просек и имеют хорошо распознаваемую линейную форму на спутниковых изображениях. При выборочной рубке из насаждения изымают часть деревьев или кустарников определённого возраста, размеров, качества или состояния. В случае выборочной рубки значения коэффициентов отражения земной поверхности могут меняться слабо, и величина изменения зависит от доли вырубленных деревьев в пологе леса. Выборочные рубки часто не так явно выявляются по спутниковым данным как сплошные, и не имеют столь четких границ на изображении. Целью данной работы была апробация разработанного инструмента детектирования изменений в лесу на двух, различающихся характером рубки, тестовых участках для определения точности его работы и его применимости для детектирования выборочных рубок леса.

\section{Характеристика тестовых участков и используемых спутниковых данных}

Метод выявления изменений был протестирован на двух разных по природным условиям тестовых участках. Один из них находится в северо-западной части Приморского края и покрывает территорию двух лесничеств, Дальнереченского и Рощинского. Площадь тестового участка составляет 25950 кв.км, средняя лесистость - 78,7\%. Тестовый участок расположен в зоне хвойно-широколиственных лесов Приамурско-Приморского хвойно-широколиственного района и таежной лесорастительной зоне Дальневосточного таежного района. Почти половина территории тестового участка располагается в части горной системы Сихотэ-Алинь. Второй тестовый участок находится на востоке Русской равнины, в европейском Приуралье, и покрывает территорию Республики Удмуртия. Тестовый участок расположен в зоне хвойношироколиственных лесов Европейской части России. Площадь тестового участка составляет 42112 кв. км, средняя лесистость - 46,2 \%. На обоих тестовых участках доминируют смешенные леса с преобладанием хвойных пород. Согласно данным лесохозяйственных регламентов, на территории первого тестового участка доминирует выборочный способ рубки (более $85 \%$ ), в то время как на территории второго преобладают сплошные рубки.

В качестве входных данных для детектирования изменений лесов использовались разновременные данные Д33, полученные системами Landsat-OLI и Sentinel-2 с пространственным разрешением 30м и 10м соответственно. Для выявления изменений лесов были выбраны следующие спектральные каналы: зеленый (533-590/537-582 нм), красный (636673/646-685 нм), ближний инфракрасный (851-879/767-908 нм). Данный набор каналов чувствителен к состоянию растительности и лежит в основе получения многих спектральных 
вегетационных индексов [4]. Для детектирования изменений в лесах преимущественно использовались данные Landsat-OLI 2015-2017 годов, полученные в период с декабря по конец февраля с наличием снежного покрова на земной поверхности. Временной интервал между парой выбранных сцен составляет примерно один год.

На тестовых участках с помощью интерактивной обработки в картографическом интерфейсе информационной системы ВЕГА-Приморье были выявлены участки вырубок 2016 года. Для повышения точности датировки и достоверности детектирования изменений лесов территория тестового участка в Приморском крае была охвачена не менее $3 \mathrm{x}$ раз разными парами спутниковых данных из используемого набора, в то время тестовый участок в Республики Удмуртия - 1-2 раза.

\section{Описание полученных результатов}

Результаты детектирования изменений были внесены в базу данных информационной системы ВЕГА-Приморье. Информация о каждом выявленном участке изменения лесов, хранящаяся в базе данных, имеет временной интервал возникновения, изначально равный временному интервалу между датами снимками, с помощью которых обнаружено изменение, а затем уточняется по мере внесения в базу данных других результатов для данной территории. Все изменения, построенные в рамках данного исследования, имели временной интервал возникновения внутри временного отрезка декабрь 2015 по февраль 2017 года. Для построения карты изменений за 2016 год из базы данных выбирались только те рубки, большая часть временного интервала возникновения которых лежала в 2016 году. Поэтому помимо рубок, произошедших в 2016 году, данная карта может содержит и рубки, случившиеся в декабре 2015 года и в январе и феврале 2017 года. На основе обработанных спутниковых данных были построены карты рубок леса за 2016 год на территории тестовых участков. Пример результатов выявления изменений лесов представлен на рисунке 1.

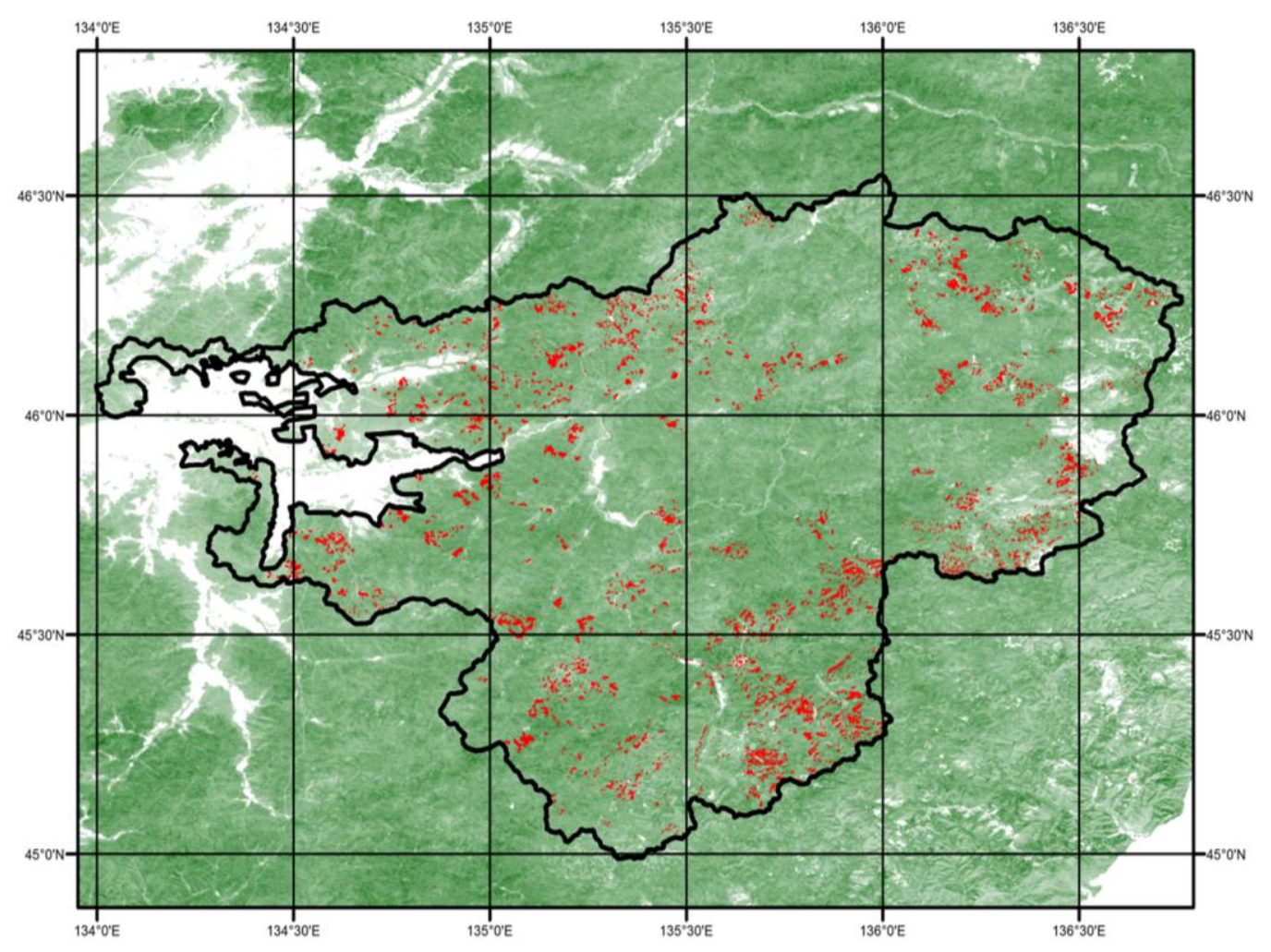

Рис. 1. Пример изменений лесов 2016 года, выявленных на территории Рощинского лесничества Приморского края 
Общая площадь выявленных рубок леса в 2016 году на территории Республики Удмуртия составила 10761,6 га. На территории тестового участка в Приморском крае были детектированы изменения на площади 20061,9 га. Полученные данные о выявленных изменениях были соотнесены с данными официальной статистики о площади рубок и представлены в таблице 1.

Таблица 1. Сравнение площади выявленных рубок с данными официальной статистики и данными GFC на двух тестовых участках

\begin{tabular}{|c|c|c|c|}
\hline \multirow{2}{*}{\multicolumn{2}{|c|}{ Сравниваемая характеристика }} & \multicolumn{2}{|c|}{ Регион тестового участка } \\
\hline & & Приморский край & Республика Удмуртия \\
\hline \multicolumn{2}{|c|}{$\begin{array}{c}\text { Пломадь рубок в } 2016 \text { году на основе } \\
\text { разработанного метода }\end{array}$} & 20061,89 га & 10761,6 га \\
\hline \multicolumn{2}{|c|}{$\begin{array}{c}\text { Площзадь рубок в } 2016 \text { году по офичиальнымм } \\
\text { даннымм }\end{array}$} & 29523,00 га & 9423,00 га \\
\hline \multirow{3}{*}{ Пломадь рубок по данным GFC } & 2015 & 3535,21 га & 6323,9 га \\
\hline & 2016 & 4910,91 га & 9244,88 га \\
\hline & 2017 & 5528,89 га & 9807,07 га \\
\hline \multirow{3}{*}{$\begin{array}{c}\text { Площадь рубок, согласованно } \\
\text { выяявленных на основе } \\
\text { разработанного метода и по } \\
\text { данным GFC }\end{array}$} & 2015 & 94,57 га & 216,58 га \\
\hline & 2016 & 1539 га & 3862,27 га \\
\hline & 2017 & 1527 га & 4013,16 га \\
\hline \multicolumn{2}{|c|}{$\begin{array}{l}\text { \% пломади рубок согласованно выявленных на } \\
\text { основе разработанного метода и по данным } G F C\end{array}$} & $15,76 \%$ & $75,2 \%$ \\
\hline
\end{tabular}

На тестовом участке в Республике Удмуртия с доминированием сплошных рубок, отношение площади детектированных изменений в лесу, связанных с рубками, к общей вырубленной площади по официальным данным составляет 114,2\%. Для тестового участка в Приморском крае с долей выборочных рубок более 85\%, аналогичный показатель равен 67,95\%. В предположении, что алгоритм детектирует все сплошные рубки, доля площади детектируемых выборочных рубок на тестовом участке в Приморском крае предположительно может достигать 54\%.

Построенные карты изменений лесов за 2016 год были сопоставлены с данными GFC (Global Forest Change), получаемыми Лабораторией GLAD географического факультета Университета Мэриленд (США) и отражающими межгодовые изменения лесного покрова планеты на основе данных Landsat с пространственным разрешением 30м [5]. Результаты сравнения также приведены в таблице 1. Согласно опубликованным данным общая точность продукта GFC для бореальных лесов составляет 83\% [6]. Для тестового участка в Республике Удмуртия площадь изменений в 2016 году по данным GFC совпадает с площадью рубок по официальным данным на 98\%. На тестовом участке в Приморском крае отношение площади изменений по данным GFC к площади рубок по официальным данным составляет 16,63\%, что может свидетельствовать об весьма ограниченной обнаружительной способности используемого при построении соответствующего информационного продукта метода применительно к выборочным рубкам.

При сравнении построенной карты изменений за 2016 год с данными GFC был использован трехлетний период с 2015 по 2017 года снижения влияния фактора точности датировки 
выявляемых изменений [5]. Однако, несмотря на расширение границ временного периода сравнения, на тестовом участке в Приморском крае имеет место низкое пространственное совпадение двух информационных продуктов, что также подтверждается таблицей 1. Так только 15,76\% площади вырубленных участков леса в Приморском крае по данным GFC согласуются с данными, полученными с помощью разработанного метода. Из таблицы 1 видно, что на тестовом участке в Республике Удмуртии 75,2\% площади выявленных изменений в лесах согласуются с данными GFC. При этом большая часть площади из 24,8\% несогласованных в обоих сравниваемых наборах данных участков изменений лесов объясняется различиями в детектировании их контуров.

\section{Анализ влияния различных факторов на точность и полноту детектируемых изменений в лесах}

Различия результатов детектирования рубок на двух тестовых участках (таблица 1) вызваны рядом причин. Во-первых, полнота и точность детектирования рубок зависит от размеров последних и преимущественно используемого в регионе способа рубки (сплошной или выборочный). Для фиксации изменений проективного покрытия полога леса с помощью спутниковых данных величина соответствующих различий значений коэффициента спектральной яркости должна превышать погрешность, вносимую другими мешающими факторами [3]. Поэтому точность детектирования участков переходных изменений, т.е. не приведших к образованию непокрытых лесом территорий, например, в результате выборочных рубок сильно зависит от выбора используемых спутниковых данных. Использование спутниковых данных, полученных в зимний период, дает возможность исключить влияние фенологических изменений состояния растительного на получаемый результат. Кроме того, в летние месяцы в Приморском крае наблюдается высокая степень облачности и, как следствие, недостаток спутниковых данных, пригодных для выявления изменений в лесах. Использование спутниковых данных зимнего периода также сопряжено с ограничениями, вызванными, в частности, пространственной неоднородностью наличия и высоты снежного покрова.

Во-вторых, пространственное разрешение спутниковых изображений накладывает ограничения на вероятность выявления выборочных рубок. Реализованный алгоритм детектирования изменений в лесах позволяет использовать спутниковые изображения различного пространственного разрешения, включая данные систем Д33 Landsat-8 (30м) и Sentinel-2A (10м). На тестовом участке в Приморском крае был проведен эксперимент по оценке влияния величины пространственного разрешения спутниковых изображений на площадь детектируемых участков изменений в лесах. Были подобраны сцены Landsat-8 и Sentinal-2A за одинаковые даты и проведено сравнение выявленных по ним контуров рубок. На основании эксперимента можно утверждать, что хотя при повышении пространственного разрешения спутниковых изображений с 30 до 10 метров площадь детектируемых изменений в лесах увеличивается незначительно (менее, чем на 1\%), контуры выявленных участков сильно меняются. При этом, пространственное совпадение, выявленных по данным Landsat-8 и Sentinal-2A, участков изменений лесов составило лишь около 60\%. Остальные $40 \%$ площади выявленных по данным Sentinel-2A изменений лесов приходятся на участки, не детектированные по данным Landsat-8. Количество выявленных связных контуров по данным Sentinal-2A возрастает более чем в 7 раз по сравнению с результатами, полученными по данным Landsat-8. Таким образом, переход к более детальному пространственному разрешению спутниковых данных способен существенно повысить уровень детальности детектируемых участков выборочных рубок.

В третьих, существенным мешающим фактором при анализе спутниковых изображений в Приморском крае является рельеф местности, особенно сильно проявляемый в данных зимнего периода съемки из-за низкой высоты Солнца. Хотя искажения вносимые рельефом местности частично компенсируются выбором близких дат разновременной спутниковой съемки, данный 
фактор оказывает значительное влияние и часто приводит к ложному выявлению изменений лесов. Для тестирования возможностей снижения влияния рельефа местности на результат выявления рубок были проведены эксперименты по топографической нормализации спутниковых изображений. Эксперименты были проведены на части тестового участка в Приморском крае с выраженным рельефом местности и активной лесозаготовкой с детектированием рубок леса в течение 2017-2018 годов по разносезонным данным Landsat-8 и Sentinel-2A. В рамках эксперимента были протестированы следующие модели топографической коррекции: C-factor, Cosine, Percent и Minnaert [7]. На основании сравнения выявленных изменений лесов и эталонных контуров рубок оценивались доли площади их пространственного совпадения и рассогласования.

Таблица 2. Влияние топографической коррекции спутниковых данных на точность и полноту детектирования рубок леса

\begin{tabular}{|c|c|c|c|}
\hline $\begin{array}{c}\text { Метод топографической } \\
\text { коррекции }\end{array}$ & $\begin{array}{c}\text { \% подтвержденных } \\
\text { изменений }\end{array}$ & $\begin{array}{c}\text { \% пропущенных } \\
\text { изменений }\end{array}$ & Каппа Коэна \\
\hline Без коррекции & 65,86 & 22,77 & 0,70 \\
\hline C-factor & 76,91 & 24,33 & 0,75 \\
\hline Cosine & 80,55 & 53,14 & 0,54 \\
\hline Мinnaert & 65,76 & 18,32 & 0,72 \\
\hline
\end{tabular}

Эксперимент показал, что использование методов C-factor, Minnaert и Percent улучшают результаты детектирования изменений на тестовом участке. Методы C-factor и Percent повышают точность детектирования на $11 \%$, при этом понижая полноту детектирования до 4\% по сравнению с использованием некорректированных данных. Метод Minnaert увеличивает полноту детектирования на 2,5\% при практически не меняющейся точности детектирования. Согласно данным эксперимента экспозиция склона существенно влияет на долю пропущенных изменений, а именно для рубок на юго-восточных склонах (экспозиция 60-240 ) доля пропущенных изменений составляет 20-30\%, в то время как для северо-западных склонов (240$60^{\circ}$ ) достигает 50\% (рисунок 2). Предложенный метод детектирования рубок демонстрирует высокую долю выявляемых изменений (75-90\%) в горных районах вне зависимости от экспозиции склона. Топографическая коррекция методом Cosine ухудшает долю подтвержденных изменений на 5-20\% вне зависимости от экспозиции склона. Применение всех рассматриваемых методов топографической коррекции уменьшает долю пропущенных изменений на юго-восточных склонах и увеличивают ее на северо-западных склонах.

\section{Заключение}

В результате апробации разработанного алгоритма детектирования изменений лесов были получены предварительные оценки точности выявления рубок в двух тестовых регионах. Помимо данных о площади и дате рубки, важно определять такие характеристики как сомкнутость насаждений и объем изъятой древесины. На дистанционную оценку данных характеристик может быть направлено развитие разработанного алгоритма. Данные об изменениях лесов, полученные на основе разработанного алгоритма, могут быть использованы для статистической оценки масштабов рубок на уровне регионов и лесничеств.

Исследование выполнено за счет гранта Российского научного фонда (проект № 19-77-30015). 

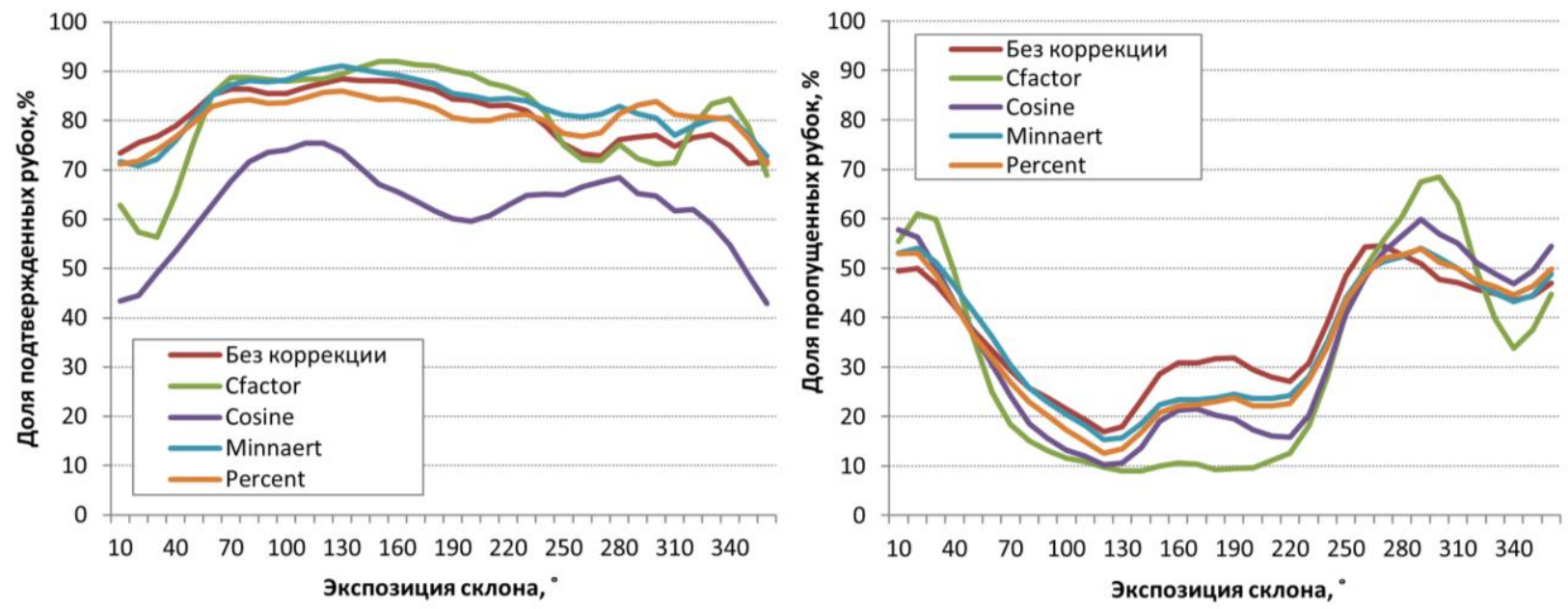

Рис. 2. Зависимость точности и полноты детектирования рубок леса от экспозиции склона на тестовом участке в Приморском крае

\section{References}

[1] Loupian E.A., Bartalev S.A., Balashov I.V., Bartalev S.S., Burtsev M.A., Egorov V.A., Efremov V.Yu., Zharko V.O., Kashnitskii A.V., Kolbudaev P.A., Kramareva L.S., Mazurov A.A., Oksyukevich A.Yu., Plotnikov D.E., Proshin A.A., Sen'ko K.S., Uvarov I.A., Khvostikov S.A., Khovratovich T.S. Vega-Primorie: complex remote forest monitoring information system, Sovremennye problemy distantsionnogo zondirovaniya Zemli iz kosmosa, 2016, 13(5), pp. 11-28. DOI: DOI: 10.21046/2070-7401-2016-13-5-11-28. (In Russian).

[2] Loupian E.A., Proshin A.A., Burtsev M.A., Balashov I.V., Bartalev S.A., Efremov V.Yu., Kashnitskii A.V., Mazurov A.A., Matveev A.M., Sudneva O.A., Sychugov I.G., Tolpin V.A., Uvarov I.A. IKI center for collective use of satellite data archiving, processing and analysis systems aimed at solving the problems of environmental study and monitoring, Sovremennye problemy distantsionnogo zondirovaniya Zemli iz kosmosa, 2015, 12(5), pp. 263-284. (In Russian).

[3] Bartalev S.A., Kuryatnikova T.S., Stibig H.J. Methods for the analysis of time-series of high-resolution satellite images for the assessment of logging in the taiga, Sovremennye problemy distantsionnogo zondirovaniya Zemli iz kosmosa, 2005, 2(2), pp. 217-227.

[4] Bannari A., Morin D., Bonn F., Huete A.R. A review of vegetation indices, Remote Sensing Reviews, 1995, 13(1), pp. 95-120. DOI: 10.1080/02757259509532298

[5] Hansen M. C., Potapov P. V., Moore R., Hancher M., Turubanova S. A., Tyukavina A., Thau D., Stehman S. V., Goetz S. J., Loveland T. R., Kommareddy A., Egorov A., . Chini L, Justice C. O., Townshend J. R. G. HighResolution Global Maps of 21st-Century Forest Cover Change, Science, 2013, 342, pp. 850-853. DOI: $10.1126 /$ science. 1244693

[6] Kim D.H., Sexton J.O., Noojipady P., Huang C., Anand A., Channan S., Feng M., Townshend J.R. Global Landsat-based forest-cover change from 1990 to 2000, Remote Sensing of Environment, 2014, 155, pp. 178-193. DOI: 10.1016/j.rse.2014.08.017

[7] Riano, D. and Chuvieco, E. and Salas, J. and Aguado, I., 2003. Assessment of Different Topographic Corrections in Landsat-TM Data for Mapping Vegetation Types. IEEE Transactions On Geoscience And Remote Sensing, 41(5), pp.1056-1061. DOI: 10.1109/TGRS.2003.811693 